\title{
Stress During Pregnancy Affects General Intellectual and Language Functioning in Human Toddlers
}

\author{
DAVID P. LAPLANTE, RONALD G. BARR, ALAIN BRUNET, GUILLAUME GALBAUD DU FORT, \\ MICHAEL L. MEANEY, JEAN-FRANÇOIS SAUCIER, PHILIP R. ZELAZO, AND SUZANNE KING

\begin{abstract}
Douglas Hospital Research Centre [D.P.L., A.B., M.J.M., S.K.], McGill University, Verdun, Canada H4H 1R3; Department of Pediatrics [R.G.B.], Montreal Children's Hospital and McGill University, Montreal, Canada H3H 1P3; Department of Psychiatry [A.B., S.K.], McGill University, Montreal, Canada H3A 1A1; Centre for Clinical Epidemiology and Community Studies Epidemiology and Biostatistics [G.G.d.F.], McGill University, Montreal, Canada H3A 1A2; Department of Psychiatry [J.-F.S.], Ste. Justine Hospital and Université de Montréal, Montreal, Canada H3T 1C5; and Department of Psychology [P.R.Z.], McGill
\end{abstract} \\ University, Montreal, Canada H3A $1 B 1$
}

\begin{abstract}
Prenatal maternal stress has been shown to impair functioning in nonhuman primate offspring. Little is known about the effects of prenatal stress on intellectual and language development in humans because it is difficult to identify sufficiently large samples of pregnant women who have been exposed to an independent stressor. We took advantage of a natural disaster (January 1998 ice storm in Québec, Canada) to determine the effect of the objective severity of pregnant women's stress exposure on general intellectual and language development of their children. Bayley Mental Development Index (MDI) scores and parentreported language abilities of 58 toddlers of mothers who were exposed to varying levels of prenatal stress were obtained at 2 y of age. The hierarchical multiple regression analyses indicated that the toddlers' birth weight and age at testing accounted for $12.0 \%$ and $14.8 \%$ of the variance in the Bayley MDI scores and in productive language abilities, respectively. More importantly, the level of prenatal stress exposure accounted for an additional
\end{abstract}

ABSTRACT

$11.4 \%$ and $12.1 \%$ of the variance in the toddlers' Bayley MDI and productive language abilities and uniquely accounted for $17.3 \%$ of the variance of their receptive language abilities. The more severe the level of prenatal stress exposure, the poorer the toddlers' abilities. The level of prenatal stress exposure accounted for a significant proportion of the variance in the three dependent variables above and beyond that already accounted for by non-ice storm-related factors. We suspect that high levels of prenatal stress exposure, particularly early in the pregnancy, may negatively affect the brain development of the fetus, reflected in the lower general intellectual and language abilities in the toddlers. (Pediatr Res 56: 400-410, 2004)

Abbreviations
PNMS, prenatal maternal stress
MDI, Mental Developmental Index
MCDI, MacArthur Communicative Development Inventory

The effects of prenatal maternal stress (PNMS) on offspring abilities have been examined extensively in nonhuman primates in well-controlled studies. In general, increases in PNMS are related to elevated levels of inhibited behavior and decreases in cognitive and neuromotor functioning $(1,2)$. For example, both chronic stress during pregnancy (1) and $2 \mathrm{wk}$ of

Received February 11, 2003; accepted March 17, 2004

Correspondence: Suzanne King, Ph.D., Douglas Hospital Research Centre, Psychosocial Unit, 6875 LaSalle Blvd., Verdun QC H4H 1R3, Canada; E-mail: suzanne.king@douglas.mcgill.ca

This study was supported by a grant from the Schizophrenia Axis of the Fonds de la recherche en santé du Québec's Network on Mental Health Research to D.P.L. and by grants from the McGill University Stairs Memorial Fund, the Canadian Psychiatric Research Foundation CIBC World Markets Children's Miracle Award Fund, and a research fellowship from the Fonds de la recherche en santé du Québec (FRSQ) to S.K.

DOI: 10.1203/01.PDR.0000136281.34035.44
ACTH administration at midgestation (2) predict poorer attention during infancy. Moreover, mild prenatal maternal stress is associated with delayed object permanence (3). In human populations, maternal anxiety (4) and moderate to severe life events $(5,6)$ during pregnancy increase the risk of obstetric complications such as preeclampsia, fetal distress, preterm birth, and low birth weight and predict an increase in neonatal crying (7), acute health problems during the first year (8), and behavioral and/or emotional problems at 4 y of age (9). Moreover, Apgar scores at $5 \mathrm{~min}$ were $2 \mathrm{SD}$ lower in newborns of anxious mothers (4), indicating birth trauma. In terms of cognitive functioning in humans, PNMS has been linked to poorer performance. For example, a study of the long-term effects of PNMS associated with a major earthquake demonstrated that 18 -y-olds who were exposed prenatally had signif- 
icantly lower nonverbal IQ scores than did a cohort born 1 year later (10). Similar results have been reported in the context of stress resulting from exposure to a war (11). Chronic stress resulting from moderate daily hassles (12) and state and/or trait anxiety (13) are also associated with delayed language development and lowered intellectual functioning, respectively.

It is interesting that the effects of PNMS on birth outcomes and postnatal development are related to the timing of the exposure. In animals, poorer outcomes are frequently associated with midgestation exposure $(1,2)$. Similar findings have been observed in studies of human populations $(14,15)$. For example, Glynn et al. (15) reported that the gestational ages of newborns whose mothers were exposed to an earthquake in their first trimester were shorter than those whose mothers were exposed in their third trimester. Thus, there may exist a critical period during prenatal development when PNMS may have more significant effects on birth outcomes and postnatal development.

Research on PNMS, however, is hampered by methodological constraints. Human studies do not allow stressful events to be randomly assigned during pregnancy and thus lack internal validity. Moreover, naturally occurring events, such as divorce, job loss, or family and marital discord, may not be independent of the woman's own personality, which may also be passed on to her children genetically. In addition, most human studies of stress have restricted variance; an extremely large sample of pregnant women is required to include a sufficient number who had experienced moderate to high levels of stress. Finally, retrospective studies such as the earthquake study (10) or the studies of war exposure (11) and moderate daily hassles (12) linking increased risk of cognitive delay to prenatal events do not include timely evaluations of the objective severity of the stress exposure at the time of the event. Moreover, the results of animal studies, which are ideal in their control of prenatal and postnatal environments, cannot be easily extrapolated to humans because humans have many potential risk and protective factors operating between the objective hardship experienced and the emotional and hormonal reactions.

Natural and human-made disasters act as "natural experiments," randomizing the distribution of stress exposure. Between January 5 and 9, 1998, the province of Québec in Canada experienced a series of freezing rain storms that resulted in the loss of electrical power to $\sim 1.5$ million homes for periods ranging between several hours to $>5 \mathrm{wk}$. The ice storm crisis was clearly a natural disaster that encompassed several of the aspects of a disaster identified by Norris (16) - scope, loss, and threat - as well as a fourth aspect assessed in the present study reflecting change. Scope is defined here as the extent to which individuals are exposed to the event. As mentioned earlier, the loss of electricity and telephone service directly related to downed power and telephone lines, because of ice build-up, ranged from only several hours to several weeks. Loss is defined here as the tangible loss of people or property. In terms of the present event, 27 deaths were directly related to the ice storm, and extensive damage to homes occurred, especially in the area from which our participants were drawn. Moreover, many individuals, particularly those from the area from which our participants were drawn, experienced loss of income as businesses and industries were forced to close for lack of electricity. Threat is defined here as an event that threatens the life or well-being of individuals. The ice storm resulted in numerous threats to the life and well-being of individuals from ice falling off of roofs of residential and commercial structures, from lack of potable water as the water treatment plants were functioning at reduced capacities, and from the build-up of carbon monoxide as many individuals were attempting to heat their residences with propane heaters. Finally, change was defined as the amount of deviation from normal routines caused by the loss of electricity. The ice storm resulted in the relocation of thousands of individuals from their homes to temporary shelters and an increase in the number of families housing guests, particularly in the area from which our participants were drawn. As such, a large sample of pregnant women in various stages of pregnancy were randomly exposed to varying degrees of storm-related hardship.

The present study offers a rare opportunity to examine the effects that quasi-randomly assigned PNMS has on general intellectual and language development, particularly because these abilities are known to be adversely affected by other preand perinatal complications, including prematurity (17); exposure to toxins such as lead, nicotine, cocaine, or radiation in utero $(18,19)$; or maternal medical problems during pregnancy, such as the onset of gestational diabetes (20). Given that performance on cognitive measures, such as the Bayley Mental Development Index (MDI) scores, in infancy are predictive of reading and spelling abilities at 8 y $(21,22)$ and general intellectual functioning in later development (23), short-term effects of PNMS may have long-term implications. Moreover, although the timing of exposure to stress has been related to birth outcomes and postnatal development $(1,2,6,14,15)$, no research to date has studied the question of timing as it relates to general intellectual and language development in human populations.

Our objective was to determine the extent to which the severity and timing of exposure to the ice storm during the pregnancy explains variance in general intellectual and language development of 2-y-olds, above and beyond perinatal factors, such as, gestational age, birth weight, birth complications, and maternal postpartum depression, and socioeconomic status, which have been associated with developmental outcomes. We hypothesized that toddlers who were born to mothers who experienced higher levels of PNMS would exhibit poorer general intellectual and language functioning. We expected that the effect of PNMS would be greatest in toddlers whose mothers were exposed to the ice storm early in their pregnancies.

\section{METHODS \\ Participants}

The research protocol for this study was approved by the Douglas Hospital Research Ethics Board and by the Research Ethics Committee of the Louis-H-Lafontaine Hospital. The toddlers in the present study represent a subsample $(n=58)$ of a prospective longitudinal study examining the potential effects 
of PNMS on pre- and perinatal birth outcomes and subsequent development of children exposed in utero (24). Because the present study was designed to provide initial analyses of potential short-term outcomes and because of budgetary limitations, 80 families were selected in which the toddler was not born prematurely and the mother had not smoked or consumed alcohol during pregnancy. Of the families identified for participation in the study, 58 participated in the present study. An additional 14 families were assessed, but their data were not included in the present analyses as the mothers became pregnant only after the completion of the ice storm. As such, the toddlers of these mothers were not subjected to the effects of the ice storm while in utero. The remaining eight families did not agree to participate in the study. The present sample was divided into trimester of gestation and gender groups. Twenty-one toddlers were in their first trimester of gestation, 14 toddlers were in their second trimester of gestation, and 23 toddlers were in their third trimester of gestation when their mothers were exposed to the ice storm. Twenty-seven of the toddlers were boys, and 31 were girls.

Sample construction. To contact as many women who were pregnant during the ice storm as possible for the parent longitudinal study, we sought the assistance of obstetricians who were associated with the four major hospitals in the Montérégie region of Quebec. To ensure the confidentiality of their patients, these obstetricians agreed to mail our first questionnaire (Reactions to the Storm) to women who met our criteria: being pregnant during the ice storm, French speaking, and $18 \mathrm{y}$ of age or older. Questionnaire 1 was sent to 1440 women. A total of 224 women $(15.6 \%)$ responded to this questionnaire. More importantly, 178 women included their name and address within Questionnaire 1 and allowed us to contact them with a follow-up questionnaire (Outcomes of the Pregnancy) 6 mo after their due date. Finally, when the children were 2 y of age, the subsample of 58 parents and their children were observed in our laboratory at the Centre de Recherche Fernand-Seguin in Montreal, Quebec, Canada.

In January 1998, mothers who agreed to participate in our study were, on average, $30 \mathrm{y}, 5$ mo old (range: 19 y, 9 mo to $41 \mathrm{y}, 7 \mathrm{mo}$ ), had completed at least grade 10, and worked, on average, $35.5 \mathrm{~h}$ per week during the preceding year. All of the respondents were either married or in a common-law union, and $81 \%$ had at least one child living with them at the time of the ice storm. All of the respondents' partners had completed at least grade 10 and worked during the preceding year. The majority of the respondents owned their own homes $(86.2 \%)$ and had a household income in excess of $\$ 40,000$ CAN (87.8\%).

Demographic composition of present sample. Age of mother, education of parents, marital status, job classification of parents, and household income were collected from the parents during our initial questionnaire survey in 1998. Socioeconomic status was computed using Hollingshead Index criteria (25). As seen in Table 1, nearly three quarters of the families in the present sample were categorized as uppermiddle or upper class. As such, the families of the toddlers in the present study are representative of the full sample of 174 families who agreed to participate in our larger longitudinal study.
Table 1. Demographic information for the subsample of the parents of the toddlers who participated in the present study

\begin{tabular}{|c|c|c|c|}
\hline Demographic variables & Percentage & Demographic variable & Percentage \\
\hline Maternal education & & Paternal education & \\
\hline High school & 8.6 & High school & 12.2 \\
\hline Junior college & 38.0 & Junior college & 49.2 \\
\hline University & 44.8 & University & 35.1 \\
\hline Postgraduate studies & 8.6 & Postgraduate studies & 3.5 \\
\hline Maternal job classification & & Paternal job classification & \\
\hline Unskilled & 12.1 & Unskilled & 0.0 \\
\hline Semiskilled & 1.7 & Semiskilled & 7.3 \\
\hline Skilled & 1.7 & Skilled & 25.5 \\
\hline Office & 24.1 & Office & 12.6 \\
\hline Semiprofessional & 13.8 & Semiprofessional & 10.9 \\
\hline Minor professional & 34.5 & Minor professional & 27.3 \\
\hline Major professional & 12.1 & Major professional & 16.4 \\
\hline \multicolumn{4}{|l|}{ Familial income } \\
\hline$\$ 6,000-\$ 11,999$ & 1.7 & & \\
\hline$\$ 12,000-\$ 19,999$ & 1.7 & & \\
\hline$\$ 20,000-\$ 29,999$ & 1.7 & & \\
\hline$\$ 30,000-\$ 39,999$ & 6.9 & & \\
\hline$\$ 40,000-\$ 49,999$ & 17.2 & & \\
\hline$\geq \$ 50,000$ & 70.7 & & \\
\hline \multicolumn{4}{|l|}{ Hollingshead classification } \\
\hline Lower class & 1.7 & & \\
\hline Middle class & 25.9 & & \\
\hline Upper middle class & 50.0 & & \\
\hline Upper class & 22.4 & & \\
\hline
\end{tabular}

\section{Predictor Variables}

Objective stress. Objective stress was estimated using the mothers' responses to questions from categories of exposure used in other disaster studies: threat, loss, scope, and change (26). Because each natural disaster presents unique experiences to the exposed population, questions pertaining to each of the four categories must be tailored-made (Table 2). Each dimension was scored on a scale of $0-8$, ranging from no exposure to high exposure. A total objective stress score was calculated by summing scores from all four dimensions using McFarlane's approach (27). Because there was no theoretical basis to believe that any one of the four dimensions of our scale was more distressing than the other dimensions and on the basis of McFarlane's study of Australian firefighters (27), each dimension was weighted equally to obtain the total score of our scale. Total objective stress scores (Storm32) ranged from 4 to 20 out of a possible of 32 points.

Subjective stress. Mothers' subjective stress was assessed using the Impact of Event Scale-Revised (IES-R) (28). This scale is one of the most widely used measures in the disaster literature for the assessment of distress after trauma. The 22-item scale describes symptoms from three categories relevant to posttraumatic stress disorder: intrusive thoughts, hyperarousal, and avoidance. Scale items were written to reflect the mothers' symptoms relative to the ice storm crisis. Participants respond on a five-point Likert scale, from "not at all" to "extremely," the extent to which the behavior describes how they felt during the preceding $7 \mathrm{~d}$. The total score was used in the analyses.

Pregnancy factors. Because perinatal factors are frequently associated with general intellectual and specific linguistic out- 
Table 2. Questions used to assess the four dimensions (threat, loss, scope, and change) of our objective stress questionnaire that the mothers completed shortly after the ice storm

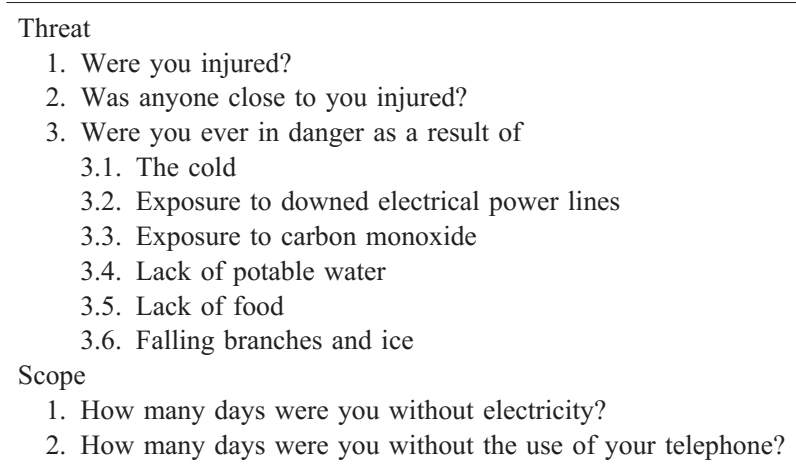

Loss

1. Did your residence suffer damage as a result of the ice storm?

2. Did you experience a loss of personal income?

3. Did you suffer a loss of business income?

\author{
Change \\ 1. Did your family stay together for the duration of the ice storm? \\ 2. Did you spend any time in a temporary shelter? \\ 3. How often were you required to change residence during the ice storm? \\ 4. Did you take in guests during the ice storm? \\ 5. Did you experience an increase in physical work during the ice storm?
}

comes (21), gestational age, birth weight, number of reported pregnancy and birth complications, and level of postpartum depression were included as potential covariates. The mothers reported gestational age and birth weights in the questionnaire that they received after the birth of their children (Outcomes of the Pregnancy Questionnaire). In the same questionnaire, the number of obstetric complications was determined by maternal recall using an adaptation of the scale used by Jacobsen and Kinney (29). The level of postpartum depression was assessed using the Edinburgh Postpartum Depression Scale (30).

\section{Dependent Variables}

Assessment of intellectual abilities. The toddlers' general intellectual abilities were assessed by trained assistants using the Mental Scale of the Bayley Scales of Infant Development (2nd Ed.) (31). The 178-item Mental Scale provides a normalized standard score, the MDI, that correlates 0.73 with later Wechsler Preschool and Primary Scale of Intelligence fullscale IQ scores. Data for the present study were available for 52 of the 58 toddlers.

Assessment of language abilities. A French adaptation of the MacArthur Communicative Development Inventory (MCDI) (32) was administered to assess the children's productive and receptive language abilities. The mothers completed the inventory by indicating which of the 100 words provided that their child either understood (receptive language) or spoke (productive language). The original adaptation of this scale was performed by Diane Poulin-Dubois and colleagues at Concordia University and was further modified for older children by the first author and Jean Séguin of Université de Montréal. MCDI data were available for 55 of the 58 toddlers.

The assistants who evaluated the toddlers' intellectual and language abilities were blind to the extent and timing of the PNMS and to the nature of all covariates.

\section{Statistical Analyses}

The following statistical procedures were performed on the data. First, descriptive analyses were performed on the three dependent and all of the predictor variables. Second, Pearson Product-Moment correlation coefficients were obtained for all pairs of dependent and predictor variables. Third, because of the relatively small sample size and because the dependent variables and the majority of predictor variables were continuous in nature, hierarchical multiple regression analyses were performed on each dependent variable. Moreover, because one of the goals of the present study was to determine whether the timing of the PNMS (i.e. month of the pregnancy when the exposure to the effects of the ice storm occurred) had an influence on subsequent development, the month of pregnancy during which the toddler was exposed to the PNMS was included in the equations. Likewise, the gender of the toddler was included in the equation. Finally, interaction terms involving level of PNMS $\times$ month of pregnancy and level of PNMS $\times$ gender were calculated and entered into the equation. A hierarchal regression model was used in which predictor variables other than level of PNMS were entered in a stepwise manner in the first block, level of PNMS entered in the second block, month of pregnancy in the third block, the interaction term of level of PNMS $\times$ month of pregnancy in the fourth block, gender in the fifth, and the interaction term of level of PNMS $\times$ gender in the final block. This method of analysis was used to determine whether the mothers' objective stress exposure in the present study accounted for variance in the dependent variables above and beyond that already accounted for by events and circumstances other than the ice storm.

\section{RESULTS}

\section{Descriptive Analyses}

The means and standard deviations of the dependent and predictor variables and covariates are listed in Table 3. On average, the toddlers' Bayley MDI scores were close to the norm of 100 , with no toddlers scoring within the mentally retarded range (i.e. below 70). On average, the toddlers' MCDI productive language scores were slightly lower than the norm of 65 words for 26-mo-old toddlers. Norms are not available for receptive language. The average gestational age and birth weight of the toddlers were within the normal ranges. On average, scores on the Edinburgh Postnatal Depression Scale were below the cut-off of 12 for clinical depression, with only four mothers scoring in the clinical level. The subjective stress 
Table 3. Descriptive statistics for the dependent and predictor variables

\begin{tabular}{lrrc}
\hline \multicolumn{1}{c}{ Variables } & Mean & SD & Range \\
\hline Bayley MDI & 99.1 & 11.6 & $72-131$ \\
MCDI Productive Language & 64.0 & 22.4 & $9-99$ \\
MCDI Receptive Language & 86.5 & 10.1 & $61-100$ \\
Objective stress (Storm32) & 10.9 & 3.3 & $4-18$ \\
Subjective stress (IES-R Total) & 9.5 & 11.3 & $0-54$ \\
Number of obstetric complications & 1.1 & 1.1 & $0-4$ \\
Postpartum depression (Edinburgh) & 5.5 & 2.6 & $0-14$ \\
Gestational age (wk) & 39.8 & 1.3 & $37-42$ \\
Birth weight (g) & 3496.9 & 437.2 & $2819-4420$ \\
Month of gestation during exposure to & 5.2 & 2.6 & $1-9$ \\
$\quad$ ice storm & & & \\
Age at testing (y, mo) & 2.2 & 0.1 & $1.1-2.4$ \\
\hline
\end{tabular}

IES-R, Impact of Event Scale-Revised.

(IES-R) scores of the mothers were, on average, 9.5, which is lower than levels obtained in response to other types of stressors reported elsewhere and below levels usually associated with clinically diagnosed posttraumatic stress disorder $(33,34)$.

\section{Intercorrelations of the Dependent and Predictor Variables}

As indicated in Table 4, the level of the mothers' degree of objective stress exposure (i.e. Storm32) was negatively correlated with each of the three dependent variables, indicating that higher levels of objectively measured hardship during the ice storm were associated with lower Bayley MDI scores and lower productive and receptive language abilities. Of the remaining predictor variables, the toddlers' birth weight was negatively correlated with the Bayley MDI scores, and their age at testing was positively correlated with the MCDI productive language scores.

\section{Hierarchical Multiple Regression Models}

Bayley MDI scores. The results of the analysis are presented in Table 5. In the first stepwise block, only the toddlers' birth weight entered the equation and accounted for $12.0 \%$ of the variance of the Bayley MDI scores: higher birth weights were associated with lower Bayley MDI scores. When the level of PNMS was added, the amount of variance accounted for rose to $23.4 \%$; controlling for the toddlers' birth weights, higher levels of PNMS were associated with lower Bayley MDI scores. Examination of the semipartial correlations for each factor indicates that the toddlers' birth weight and the level of PNMS uniquely accounted for $8.6 \%$ and $11.4 \%$ of the variance, respectively. The toddlers' birth weight and the level of PNMS jointly accounted for the remaining 3.4\% of the variance. As such, the unique contribution of the toddlers' birth weight was reduced once the level of PNMS was entered into the model. The addition of the month of pregnancy during which the toddlers were exposed to the effects of the ice storm did not significantly increase the amount of variance accounted for. However, the addition of the level of PNMS $\times$ month of pregnancy interaction term in step 4 increased the amount of variance accounted for to $32.5 \%$. According to the semipartial correlations, the toddlers' birth weight and the level of PNMS uniquely accounted for $9.9 \%$ and $14.8 \%$ of the variance, respectively, after the interaction term of the level of PNMS $\times$ month of pregnancy was entered into the model. The interaction term of the level of PNMS $\times$ month of pregnancy accounted for $7.7 \%$ of the variance. The remaining $0.1 \%$ of the variance was jointly accounted for by the three variables. As such, the unique contribution of the toddlers' birth weight was reduced from its initial level once the interaction term of the level of PNMS $\times$ month of pregnancy interaction term was entered into the model. On the other hand, the unique contribution of the level of PNMS was increased after the introduction of the level of PNMS $\times$ month of pregnancy interaction term was entered into the model. The addition of the toddlers' gender and the level of PNMS $\times$ gender interaction term did not significantly increase the amount of variance accounted for.

Because the level of PNMS $\times$ month of pregnancy interaction accounted for a significant proportion of the variance of

Table 4. Intercorrelations among dependent variables and potential predictor variables (n varies from 52 to 58)

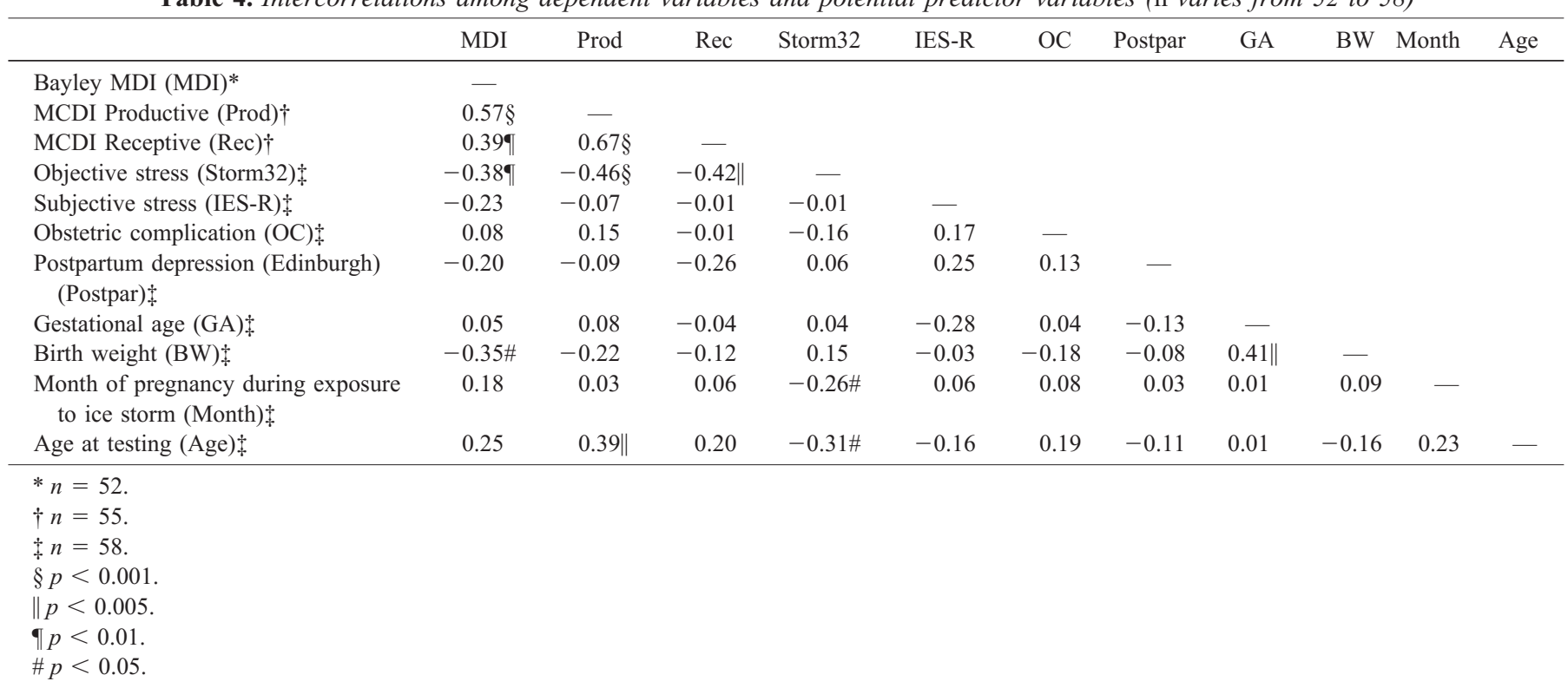


Table 5. Hierarchical regression analyses between the predictor variables and Bayley MDI scores

\begin{tabular}{|c|c|c|c|c|c|c|c|}
\hline Predictor variables & $\beta$ & $\mathrm{sr}$ & $R$ & $R^{2}$ & $\Delta R^{2}$ & $F$ & $\Delta F$ \\
\hline Step $1^{*}$ & & & 0.346 & 0.120 & & $6.79 * *$ & \\
\hline Birth weight & $-0.346^{* *}$ & -0.346 & & & & & \\
\hline Step $2 \dagger$ & & & 0.484 & 0.234 & 0.114 & $7.48 \#$ & $7.31 \#$ \\
\hline PNMS (Storm32) & $-0.342 * *$ & -0.338 & & & & & \\
\hline Step $3 \ddagger$ & & & 0.498 & 0.248 & 0.014 & $5.29 \#$ & 0.92 \\
\hline Birth weight & $-0.310^{* *}$ & -0.305 & & & & & \\
\hline Step $4 \S$ & & & 0.570 & 0.325 & 0.077 & $5.67 \#$ & $5.37 * *$ \\
\hline Birth weight & $-0.320 * *$ & -0.315 & & & & & \\
\hline PNMS (Storm32) & $-0.837 \#$ & -0.385 & & & & & \\
\hline Month of gestation & -0.752 & -0.226 & & & & & \\
\hline PNMS $\times$ month of gestation & $0.946^{* *}$ & 0.278 & & & & & \\
\hline Step $5 \|$ & & & 0.578 & 0.334 & 0.009 & $4.60 \#$ & 0.62 \\
\hline Gender & 0.104 & 0.095 & & & & & \\
\hline Step 6ף & & & 0.583 & 0.340 & 0.006 & $3.87 * *$ & 0.42 \\
\hline Birth weight & $-0.337 * *$ & -0.328 & & & & & \\
\hline PNMS (Storm32) & -0.516 & -0.135 & & & & & \\
\hline Month of gestation & -0.755 & -0.209 & & & & & \\
\hline PNMS $\times$ month of gestation & $0.973 * *$ & -0.246 & & & & & \\
\hline Gender & 0.404 & -0.101 & & & & & \\
\hline PNMS $\times$ gender & -0.391 & -0.078 & & & & & \\
\hline
\end{tabular}

$* \operatorname{df}(1,50)$

$\dagger \mathrm{df}(2,49)$

$\ddagger \mathrm{df}(3,48)$

$\S \mathrm{df}(4,47)$

$\| \operatorname{df}(5,46)$

I $\mathrm{df}(6,45)$

$\# p<0.01$

$* * p<0.05$

the Bayley MDI scores, the sample was regrouped using trimester of pregnancy at the time of the exposure [i.e. first trimester (months 1-3), second trimester (months 4-6), and third trimester (months 7-9)], and regression analyses using the toddlers' birth weight and the level of PNMS were conducted separately for participants in each trimester of pregnancy category. As indicated in Table 6, the toddlers' birth weight was not significantly related to the Bayley MDI scores for toddlers who were exposed to the ice storm when their mothers were in either their first or second trimester of pregnancy. The toddlers' birth weight did, however, account for $25.3 \%$ of the variance of the Bayley MDI scores for toddlers who were exposed to the ice storm when their mothers were in their third trimester of pregnancy: toddlers who had higher birth weights and were exposed to the effects of the ice storm when their mothers were in their third trimester of pregnancy exhibited lower Bayley MDI scores. However, the level of PNMS accounted for $27.5 \%$ and $41.4 \%$ of the variance in the Bayley MDI scores, above and beyond that already attributed to the toddlers' birth weight for toddlers who were exposed to the ice storm when their mothers were in their first and second trimesters of pregnancy, respectively. In both instances, higher levels of PNMS were associated with lower Bayley MDI scores. The level of PNMS did not significantly account for any additional variance of the Bayley MDI scores for the toddlers who were exposed to the ice storm when their mothers were in their third trimester of pregnancy.

MCDI productive language scores. The results of this analysis are presented in Table 7. From the first, stepwise block of control variables, only the toddlers' age at testing remained in the equation and accounted for $14.8 \%$ of the variance of the MCDI productive language scores: older toddlers produced more words. The addition of the level of PNMS in step 2 increased the amount of variance accounted for to $26.9 \%$ : higher levels of PNMS were associated with lower word production. Inspection of the semipartial correlations indicates that after the introduction of the level of PNMS into the model at step 2, the toddlers' age at testing and the level of PNMS uniquely accounted for $6.2 \%$ and $12.1 \%$ of the variance, respectively. Together, these variables jointly accounted for the remaining $8.7 \%$ of the variance. As such, the unique contribution of the toddlers' age at testing in explaining their productive language abilities declined after the introduction of the level of PNMS into the model. The introduction of the remaining predictor variables into the equation did not significantly increase the proportion of the variance accounted for in the MCDI productive language scores.

MCDI receptive language scores. The results are presented in Table 8. None of the initial predictor variables remained in the equation. The level of the PNMS accounted for a signifi- 
Table 6. Hierarchical regression analyses between the toddlers' birth weight and PNMS and the Bayley MDI scores for toddlers who were exposed to the ice storm during the first, second, and third trimesters of gestation

\begin{tabular}{|c|c|c|c|c|c|c|c|}
\hline Predictor variables & $\beta$ & $\mathrm{sr}$ & $R$ & $R^{2}$ & $\Delta R^{2}$ & $F$ & $\Delta F$ \\
\hline \multicolumn{8}{|l|}{ First trimester exposure } \\
\hline Step $1^{*}$ & & & 0.145 & 0.021 & & 0.36 & \\
\hline Birth weight & -0.145 & -0.145 & & & & & \\
\hline Birth weight & -0.130 & -0.130 & & & & & \\
\hline PNMS (Storm32) & $-0.524 * *$ & -0.524 & & & & & \\
\hline \multicolumn{8}{|c|}{ Second trimester exposure } \\
\hline Step $2 \S$ & & & 0.773 & 0.598 & 0.414 & $7.44 \#$ & $10.29 \#$ \\
\hline Birth weight & -0.072 & -0.063 & & & & & \\
\hline PNMS (Storm32) & $-0.736 \#$ & -0.643 & & & & & \\
\hline \multicolumn{8}{|l|}{ Third trimester exposure } \\
\hline Step $1 \|$ & & & 0.503 & 0.253 & & $6.11 * *$ & \\
\hline Birth weight & $-0.503 \#$ & -0.503 & & & & & \\
\hline
\end{tabular}

$* \operatorname{df}(1,17)$

$\dagger \mathrm{df}(2,16)$

$\ddagger \mathrm{df}(1,11)$

$\S \operatorname{df}(2,10)$

\|df $(1,18)$

- $\operatorname{df}(2,19)$

\# $p<0.01$

** $p<0.05$

Table 7. Hierarchical regression analyses between the predictor variables and MCDI productive language scores

\begin{tabular}{|c|c|c|c|c|c|c|c|}
\hline Predictor variables & $\beta$ & $\mathrm{sr}$ & $R$ & $R^{2}$ & $\Delta R^{2}$ & $F$ & $\Delta F$ \\
\hline Step $1 *$ & & & 0.385 & 0.148 & & $9.22 \#$ & \\
\hline Age at testing & $0.385 \#$ & 0.385 & & & & & \\
\hline Step $2 \dagger$ & & & 0.519 & 0.269 & 0.121 & $9.56 \#$ & $8.58 \#$ \\
\hline PNMS (Storm32) & $-0.368 \#$ & -0.347 & & & & & \\
\hline Step $3 \ddagger$ & & & 0.542 & 0.293 & 0.024 & $7.06 \#$ & 1.77 \\
\hline Age at testing & $0.301 * *$ & 0.277 & & & & & \\
\hline Step $4 \S$ & & & 0.542 & 0.294 & 0.001 & $5.21 \#$ & 0.07 \\
\hline Age at testing & $0.295 \#$ & 0.266 & & & & & \\
\hline PNMS (Storm32) & -0.343 & -0.161 & & & & & \\
\hline Month of gestation & -0.066 & -0.019 & & & & & \\
\hline PNMS $\times$ month of gestation & -0.106 & -0.031 & & & & & \\
\hline Step $5 \|$ & & & 0.571 & 0.326 & 0.031 & $4.73 \#$ & 2.28 \\
\hline Gender & 0.198 & 0.177 & & & & & \\
\hline Step $6 \square$ & & & 0.572 & 0.328 & 0.002 & $3.90 \#$ & 0.14 \\
\hline Age at testing & $0.276^{* *}$ & 0.242 & & & & & \\
\hline PNMS (Storm32) & -0.061 & -0.016 & & & & & \\
\hline Month of gestation & 0.043 & 0.011 & & & & & \\
\hline PNMS $\times$ month of gestation & -0.230 & -0.055 & & & & & \\
\hline Gender & 0.369 & 0.092 & & & & & \\
\hline PNMS $\times$ gender & -0.233 & -0.044 & & & & & \\
\hline
\end{tabular}

$* \operatorname{df}(1,53)$

$\dagger \mathrm{df}(2,52)$

$\ddagger \mathrm{df}(3,51)$

$\S \mathrm{df}(4,50)$

$\| \operatorname{df}(5,49)$

ๆ $\mathrm{df}(6,48)$

$\# p<0.01$

$* * p<0.05$ 
Table 8. Hierarchical regression analyses between the predictor variables and MCDI receptive language scores

\begin{tabular}{|c|c|c|c|c|c|c|c|}
\hline Predictor variables & $\beta$ & $\mathrm{sr}$ & $R$ & $R^{2}$ & $\Delta R^{2}$ & $F$ & $\Delta F$ \\
\hline Step $1^{*}$ & & & 0.416 & 0.173 & & $11.11 \#$ & \\
\hline PNMS (Storm32) & $-0.416 \#$ & -0.416 & & & & & \\
\hline Step $2 \dagger$ & & & 0.419 & 0.176 & 0.002 & $5.54 \#$ & 0.15 \\
\hline Month of gestation & -0.050 & -0.048 & & & & & \\
\hline Step $3 末$ & & & 0.419 & 0.176 & 0.000 & $3.62 * *$ & 0.00 \\
\hline PNMS (Storm32) & -0.421 & -0.197 & & & & & \\
\hline Step $4 \S$ & & & 0.481 & 0.231 & 0.056 & $3.76 \#$ & 1.41 \\
\hline PNMS (Storm32) & -0.218 & -0.095 & & & & & \\
\hline Month of gestation & 0.166 & 0.048 & & & & & \\
\hline PNMS $\times$ month of gestation & -0.279 & -0.078 & & & & & \\
\hline Gender & 0.262 & 0.236 & & & & & \\
\hline Step $5 \|$ & & & 0.482 & 0.232 & 0.001 & $2.97 * *$ & 0.06 \\
\hline PNMS $\times$ gender & 0.151 & 0.030 & & & & & \\
\hline
\end{tabular}

$* \mathrm{df}(1,53)$

$\dagger \mathrm{df}(2,52)$

$\pm \mathrm{df}(3,51)$

$\S \mathrm{df}(4,50)$

$\| \operatorname{df}(5,49)$

$\# p<0.01$

$* * p<0.05$

cant proportion of the MCDI receptive language scores, explaining $17.3 \%$ of the variance. Higher levels of PNMS were associated with fewer words understood.

\section{DISCUSSION}

The main goal of the study was to determine whether the degree and timing of the mothers' objective stress exposure explained a significant portion of their toddlers' general intellectual and specific language abilities at $2 \mathrm{y}$ of age after controlling for the predictive power of other factors. Only the toddlers' birth weight, age at testing, and the level of PNMS were significantly correlated with the dependent variables. Measures of parental socioeconomic status, maternal level of postpartum depression, maternal subjective reaction to the ice storm, the number of obstetric complications reported by the mother, month of pregnancy during exposure, and gestational age at birth were not significantly related to any of the three dependent variables. As clearly seen in the hierarchical multiple regression analyses, the degree of the mothers' objective stress exposure accounted for a significant proportion of the explained variance, above and beyond that already explained by the toddlers' birth weight and age at testing. For the three dependent variables, high levels of PNMS were associated with poorer general intellectual and language outcomes at $2 \mathrm{y}$ of age.

The toddlers' birth weight was significantly negatively related to the Bayley MDI scores, accounting for $12 \%$ of the variance. The direction the relationship indicated that the heavier the toddlers were at birth, the lower their Bayley MDI scores at $2 \mathrm{y}$ of age. Although the direction of the relationship differed from those obtained by Siegel et al. $(21,35)$, it must be noted that the present sample was restricted only to toddlers who were born at full term. In the previous studies, the relationship with birth weight and intellectual abilities was limited to preterm infants only. In the present study, the lowest Bayley MDI scores were observed for toddlers whose birth weights were $>4000 \mathrm{~g}$. Birth weights $>4000 \mathrm{~g}$ or large for gestational age birth weights are frequently associated with birth trauma, including perinatal anoxia $(36,37)$. In turn, perinatal anoxia is associated with reduced cognitive abilities in singleton and twin populations $(38,39)$. Therefore, it is possible that the observed findings in the present study occurred because the toddlers' with the heavier birth weights may have sustained a high rate of birth anoxia, which was partly responsible for their lower Bayley MDI scores. However, this remains speculative at best because the relationship was observed only for toddlers who were exposed to the ice storm when their mothers were in their third trimester of pregnancy. Birth weight was not associated with the Bayley MDI scores for toddlers who were exposed to the ice storm when their mothers were in their first and second trimesters of pregnancy.

The toddlers' age at testing accounted for $14.8 \%$ of the variance of their productive language abilities as measured by the MCDI. As expected, the direction of the relationship indicated that the older the toddlers were during the administration of the MCDI, the more words they spoke. Although age at testing was related to the number of words spoken, age at testing was not significantly related to the number of words understood but not spoken by the toddlers.

More importantly for the goal of the present study, the level of PNMS accounted for $11.4 \%$ and $12.1 \%$ of the variance of the toddlers' general intellectual and productive language abil- 
ities, respectively, above and beyond that already accounted for the toddlers' birth weight and age at testing. The level of PNMS also accounted for $17.3 \%$ of the variance of the toddlers' receptive language abilities. Toddlers of mothers who experienced higher levels of objective stress exposure as a result of the ice storm exhibited lower MDI scores on the Bayley Scales of Infant Development, spoke fewer words, and understood (but did not yet speak) fewer words, as measured by our adapted MCDI scale, than toddlers of mothers who experienced lower levels of objectively defined prenatal stress.

Moreover, the timing of the toddlers' exposure to their mothers' objective stress during the ice storm seems to have had an important moderating effect of the PNMS on the toddlers' intellectual abilities only. Toddlers who were exposed to moderate to high levels of PNMS when their mothers were in their first or second trimester of pregnancy exhibited lower Bayley MDI scores than toddlers who had similar timing of the ice storm exposure and whose mothers experienced lower levels of PNMS. Levels of PNMS accounted for 27.5\% and $41.4 \%$ of the variance of the Bayley MDI scores for toddlers who were exposed during their first or second trimester of prenatal development, respectively, but only an additional and nonsignificant $1.2 \%$ when the exposure occurred when the mothers were in their third trimester of their pregnancies. This finding supports previous research $(14,15)$ suggesting that mothers become less sensitive to the potential effects of stressful events as their pregnancies progress into the final trimester.

In terms of the toddlers' language skills, the degree of objective stress exposure was negatively correlated with the number of words that their toddlers spoke and understood (but did not speak) at $2 \mathrm{y}$ of age. The analyses indicate that the mothers' level of prenatal stress accounted for $12.1 \%$ and $17.3 \%$ of the variance of their toddlers' productive and receptive language abilities, respectively. Unlike the findings for the toddlers' general intellectual abilities, the timing of the exposure was not related to the toddlers' language abilities.

It is widely known that exposure to various teratogens during critical periods of prenatal development result in unfavorable outcomes and account for $\sim 10 \%$ of all human birth defects (40). The above results clearly demonstrate that PNMS has a negative impact on development within the first $2 \mathrm{y}$ of life. Our findings strongly suggest that the greater the amount of objectively defined hardship faced by a pregnant woman as the result of a natural disaster, the greater the likelihood that her child will exhibit poorer outcomes at $2 \mathrm{y}$ of age, all else being equal. Even after the influence of factors known to be associated with toddlers' intellectual (e.g. birth weight) and productive language (e.g. current age) abilities were accounted for, the level of PNMS almost doubled the amount of variance accounted for in both dependent variables. Finally, the significant level of PNMS and month of pregnancy interaction observed for the Bayley MDI scores suggests that exposure to PNMS during the initial months of pregnancy may result in the most severe consequences. Our findings support the conclusion of Glynn et al. (15) indicating that prenatal maternal stress has potential teratogenic effects on the development of the fetus, which may have postnatal consequences, particularly if the insult occurs early in the pregnancy. Therefore, high levels of PNMS resulting from a naturally occurring event outside the control of pregnant women can be used as a potential marker of subsequent developmental problems in children in much the same manner as maternal personality factors have been associated with problems in development (41-44). Thus, an event independent of a pregnant woman's psychological status seems also to have a negative impact on the fetus' subsequent postnatal development.

Although the present study cannot directly identify the mechanism by which PNMS influences the fetus's postnatal development, research using nonhuman primates and other animals provides a possible explanation. In animals, PNMS is known to alter brain development through its impact on placental functioning (45-47). Acute and chronic stress depletes the placenta's ability to protect the fetus against teratogens, such as maternal cortisol, increasing the risk of permanent neurological impairments $(45,47)$. This is particularly true when fetuses are exposed early in the pregnancy (45), when cortical structures are initially forming and before the placenta begins producing the enzyme $11 \beta$-hydroxysteroid dehydrogenase, which converts noxious cortisol to benign cortisone (48). A similar process may also occur when pregnant women are exposed to high levels of stress, as was the case for many women in the present study. However, a more thorough examination of this potential relationship is required in humans before any definite causal links between PNMS and problems in cortical development can be elucidated.

The above findings indicate that moderate to high levels of PNMS have a negative impact on development during the first 2 y of life; however, several limitations exist with the present study. First, the results and conclusions are based on a relatively small number of toddlers. Although we were able to identify 1440 pregnant women who lived in the area most affected by the ice storm (the area from which we drew our participants), only $15.6 \%$ replied to our initial questionnaire. Thus, the large-scale longitudinal study from which the present sample was obtained is probably not a representative sample of the population of the targeted area. Likewise, limited funding in the early stages of the present study required that we restrict the sample for the current study to only 58 participants. As such, the obtained results, although extremely interesting, are based solely on the experiences of a small number of toddlers whose mothers were exposed to the ice storm and therefore may not be generalizable to the general population. Second, although we made every effort to construct a sample of toddlers whose mothers reported not having smoked or consumed alcohol during their pregnancies, our information was obtained from self-report questionnaire, for which accuracy is always a concern. Likewise, the mothers may not have accurately reported other prenatal complications, such as gestational diabetes, in our survey. Third, there is a strong need for replication of the present findings. Although the present findings are similar to those obtained with nonhuman primates and other animals, direct comparisons between animals and humans are not possible. Before it can be concluded satisfactorily that PNMS resulting from an event outside the woman's control can alter the postnatal development of her exposed fetus, 
additional studies using human populations need to be conducted. Moreover, these studies should involve a larger number of pregnant women than were observed in the present study. Finally, the present study only describes the outcomes of toddlers who were exposed to varying degrees of PNMS at 2 years of age. Repeated assessments of these children are required to determine whether the observed relationship between the level of PNMS and postnatal outcomes are maintained, strengthened, or decreased in magnitude over time. We are presently conducting a follow-up study of the intellectual, language, behavioral, and neuromotor development of the full sample of 174 families now that the children are $6.5 \mathrm{y}$ of age. The findings of this study will determine whether the influence of PNMS on the toddlers' intellectual and language abilities has long-term affects on development across a wider range of abilities.

Regardless of the limitations of the present study, we believe that the present findings are of great importance for several reasons. First, unlike the majority of studies examining the effects of prenatal stress on postnatal outcomes, the stressful event in the present study was independent of the women's personality factors. We believe that a naturally occurring stressful event, such as the ice storm, provides a purer measure of prenatal stress in which the timing of the stress exposure can be better identified. Second, we were able to obtain detailed descriptions of the women's experiences during the ice storm within $6 \mathrm{mo}$ of the end of the crisis, in many instances before the women gave birth. We therefore are relatively confident that the women provided accurate descriptions of their experiences. Moreover, the early acquisition of these experiences ensures that they were not reinterpreted by the women on the basis of their children's intellectual and language abilities at $2 \mathrm{y}$ of age. Third, great care was taken to obtain a sample of toddlers who were not exposed to other major teratogenic influences (e.g. alcohol, nicotine) or who were born prematurely. Although replication is still required, we are confident that the lowered general intellectual and language abilities were the result of the stress events that the pregnant women encountered during the ice storm. Thus, the present study has identified yet another factor that seems to play a major role in the development of general intellectual and specific language abilities during early infancy, namely prenatal maternal stress. Finally, the present study suggests that the timing of the exposure to PNMS may result in differential outcomes, with earlier exposure to PNMS possibly leading to more detrimental outcomes. Our continuing assessment of families in our longitudinal research project may provide us with a better understanding of the role that PNMS has on the long-term development of fetuses who are exposed to varying degrees of PNMS because of a naturally occurring disaster outside the control of pregnant women.

Acknowledgments. We thank Cheryl Chanson and Shannon Woo for entering data from the first two mail questionnaires and Claudine Leblanc and Véronique Parent for assistance in collecting the data on the toddlers.

\section{REFERENCES}

1. Schneider ML, Cole CL 1993 Repeated social stress during pregnancy impairs neuromotor development in the primate infant. J Dev Behav Pediatr 14:81-87

2. Schneider ML, Cole CL, Lubach GR 1992 Endocrine activation mimics the adverse effects of prenatal stress on the neuromotor development of the infant primate. Dev Psychobiol 15:427-439

3. Schneider ML 1992 Delayed object permanence development in prenatally stressed rhesus monkey infants Macaca mulatta. Occup Ther J Res 12:96-110

4. Crandon AJ 1979 Maternal anxiety and obstetric complications. J Psychosom Res 23:109-111

5. Lou HC, Hansen D, Nordentoft M, Pryds O, Jensen F, Nim J, Hemmingsen R 1994 Prenatal stressors of human life affect fetal brain development. Dev Med Child Neurol 36:826-832

6. Wadhwa PD, Sandman CA, Porto M, Dunkel-Schetter C, Garite TJ 1993 The association between prenatal stress and infant birth weight and gestational age at birth: a prospective investigation. Am J Obstet Gynecol 169:858-865

7. Van den Bergh BR 1990 The influence of maternal emotions during pregnancy on fetal and neonatal behavior. Pre Perinat Psychol 5:119-130

8. Goldman SL, Owen MT 1994 The impact of parental trait anxiety on the utilization of health care services in infancy: a prospective study. J Pediatr Psychol 19:369-381

9. O'Connor TG, Heron J, Golding J, Beveridge M, Glover V 2002 Maternal antenatal anxiety and children's behavioural/emotional problems at 4 years. Report from the Avon Longitudinal Study of Parents and Children. Br J Psychiatry 180:502-508

10. Watson JB, Mednick SA, Wang X 1997 Cognitive Functioning in Offspring Following Severe Prenatal Stress. Society for Research in Psychopathology, Palm Springs, $\mathrm{CA}$

11. Meijer A 1985 Child psychiatric sequelae of maternal war stress. Acta Psychiatr Scand 72:505-511

12. Scott DH 1973 Follow-up study from birth of the effects of prenatal stresses. Dev Med Child Neurol 15:770-787

13. Brouwers EPM, van Baar EL, Pop VJM 2001 Maternal anxiety during pregnancy and subsequent infant development. Infant Behav Dev 24:95-106

14. Kammerer M, Adams D, Castelberg Bv B, Glovert V 2002 Pregnant women become insensitive to cold stress. BMC Pregnancy Childbirth 2:8

15. Glynn LM, Wadhwa PD, Dunkel-Schetter C, Chicz-Demet A, Sandman CA 2001 When stress happens matters: effects of earthquake timing on stress responsivity in pregnancy. Am J Obstet Gynecol 184:637-642

16. Norris FH 1990 Screening for traumatic stress: a scale for use in the general population. J Appl Soc Psychol 20:1704-1718

17. Rose SA 1981 Lags in the cognitive competence of prematurely born infants. In Friedman S, Sigman M (eds) Preterm Birth and Psychological Development. Academic Press, New York, pp 255-269

18. Fried PA, O'Connell CM, Watkinson B 1992 60- and 72-month follow-up of children prenatally exposed to marijuana, cigarettes, and alcohol: cognitive and language assessment. J Dev Behav Pediatr 13:383-391

19. Jacobson SW, Jacobson JL 2000 Teratogenic insult and neurobehavioral function in infancy and childhood. In: Nelson CA (ed) The Minnesota Symposia on Child Psychology. Lawrence Erlbaum Associates, Mahwah, pp 61-112

20. Sells CJ, Robinson NM, Brown Z, Knopp RH 1994 Long-term developmental follow-up of infants of diabetic mothers. J Pediatr 125:S9-S17

21. Siegel LS 1982 Reproductive, perinatal, and environmental factors as predictors of the cognitive and language development of preterm and full-term infants. Child Dev 53:963-973

22. Siegel LS 1989 A reconceptualization of prediction from infant test scores. In: Bornstein MH, Krasnegor NA (eds) Stability and Continuity in Mental Development: Behavioral and Biological Perspectives. Lawrence Erlbaum Associates, Hillsdale, pp $87-103$

23. Humphreys LG, Davey TC 1988 Continuity in intellectual growth from 12 months to 9 years. Intelligence 12:183-197

24. King S, Barr RG, Brunet A, Saucier J-F, Meaney M, Woo S, Chanson C 2000 La tempête de verglas: une occasion d'étudier les effets du stress prénatal chez l'enfant et la mère. Santé mentale au Québec XXV:163-184

25. Hollingshead AB 1973 Four-Factor Index of Social Status. Yale University Press, New Haven

26. Bromet E, Dew MA 1995 Review of psychiatric epidemiologic research on disasters. Epidemiol Rev 17:113-119

27. McFarlane AC 1988 Relationship between psychiatric impairment and a natural disaster: the role of distress. Psychol Med 18:129-139

28. Weiss DS, Marmar CR 1997 The Impact of Event Scale-Revised. Guilford, New York

29. Jacobsen B, Kinney DK 1980 Perinatal complications in adopted and non-adopted samples of schizophrenics and controls. Acta Psychiatr Scand 62:337-346

30. Cox JL, Holden JM, Sagovsky R 1987 Detection of postnatal depression. Development of the 10-item Edinburgh Postnatal Depression Scale. Br J Psychiatry 150:782786

31. Bayley N 1993 Bayley Scales of Infant Development, 2nd Ed. The Psychological Corporation, San Antonio

32. Fenson L, Dale PS, Reznick JS, Thal D, Bates E, Hartung JP, Pethick S, Reilly JS 1993 MacArthur Communicative Development Inventories. Singular Publishing Group, San Diego

33. Kimerling R, Calhoun KS, Forehand R, Armistead L, Morse E, Morse P, Clark R, Clark L 1999 Traumatic stress in HIV-infected women. AIDS Educ Prev 11:321-330

34. Asukai N, Kato H, Kawamura N, Kim Y, Yamamoto K, Kishimoto J, Miyake Y, Nishizono-Maher A 2002 Reliability and validity of the Japanese-language version of 
the Impact Of Event Scale-Revised (IES-R-J): four studies of different traumatic events. J Nerv Ment Dis 190:175-182

35. Siegel LS, Saigal S, Rosenbaum P, Morton RA, Young A, Berenbaum S, Stoskopf B 1982 Predictors of development in preterm and full-term infants: a model for detecting the at risk child. J Pediatr Psychol 7:135-147

36. Dollberg S, Marom R, Mimouni FB, Yeruchimovich M 2000 Normoblasts in large for gestational age infants. Arch Dis Child Fetal and Neonatal Ed 83:F148-F149

37. Adams KM, Li H, Nelson RL, Ogburn PL Jr, Danilenko-Dixon DR 1998 Sequelae of unrecognized gestational diabetes. Am J Obstet Gynecol 178:1321-1332

38. Raz S, Shah F, Sander CJ 1996 Differential effects of perinatal hypoxic risk on early developmental outcome: a twin study. Neuropsychology 10:429-436

39. Stevens CP, Raz S, Sander CJ 1999 Peripartum hypoxic risk and cognitive outcome: a study of term and preterm birth children at early school age. Neuropsychology 13:598-608

40. Seaver LH 2002 Adverse environmental exposures in pregnancy: teratology in adolescent medicine practice. Adolesc Med 13:269-29

41. Murray L, Cooper PJ 1997 Postpartum depression and child development. Psychol Med 27:253-260
42. Sameroff AJ, Seifer R, Barocas R, Zax M, Greenspan S 1987 Intelligence quotient scores of 4-year-old children: social-environmental risk factors. Pediatrics 79:343350

43. Sameroff AJ, Seifer R, Zax M 1982 Early development of children at risk for emotional disorder. Monogr Soc Res Child Dev 47:1-82

44. Seifer R, Sameroff AJ, Dickstein S, Keitner G, Miller I, Rasmussen S, Hayden LC 1996 Parental psychopathology, multiple contextual risks, and one-year outcomes in children. J Clin Child Psychol 15:423-435

45. Avishai-Eliner S, Brunson KL, Sandman CA, Baram TZ 2002 Stressed-out, or in (utero)? Trends Neurosci 25:518-524

46. Uno H, Tarara R, Else J, Sulemen MA, Sapolsky RM 1989 Hippocampal damage associated with prolonged and fatal stress in primates. J Neurosci 9:1705-1711

47. Uno H, Eisele S, Sakai A, Shelton S, Baker E, DeJesus O, Holden J 1994 Neurotoxicity of glucocorticoids in the primate brain. Horm Behav 28:336-348

48. Welberg LA, Seckl JR 2001 Prenatal stress, glucocorticoids and the programming of the brain. J Neuroendocrinol 13:113-128 